2016-12-09

\title{
Adaptive Environments for Enabling Senior Citizens: An Holistic Assessment Tool for Housing Design and loT-based Technologies
}

\author{
Matteo Zallio \\ Technological University Dublin, matteo.zallio@tudublin.ie \\ Damon Berry \\ Technological University Dublin, damon.berry@tudublin.ie \\ Niccolò Casiddu \\ University of Genoa, casiddu@arch.unige.it
}

Follow this and additional works at: https://arrow.tudublin.ie/engscheleart

Part of the Architectural Engineering Commons, Architectural Technology Commons, Electrical and Electronics Commons, Environmental Design Commons, Industrial and Product Design Commons, and the Interior Architecture Commons

\section{Recommended Citation}

Zallio, M., Berry, D. and Cassiddu, N. (2017) Adaptive Environments for Enabling Senior Citizens: An Holistic Assessment Tool for Housing Design and loT-based Technologies. 2016 IEEE 3rd World Forum on Internet of Things (WF-IoT) - Reston, VA, USA, 12-14 December 2016. doi:10.1109/WF-IoT.2016.7845463

This Conference Paper is brought to you for free and open access by the School of Electrical and Electronic Engineering at ARROW@TU Dublin. It has been accepted for inclusion in Conference papers by an authorized administrator of ARROW@TU Dublin. For more information, please contact arrow.admin@tudublin.ie, aisling.coyne@tudublin.ie,gerard.connolly@tudublin.ie.

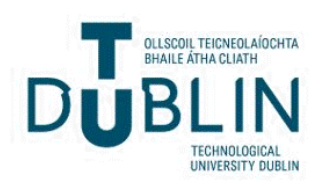




\title{
Adaptive Environments for Enabling Senior Citizens:
}

\author{
An Holistic Assessment Tool for Housing Design and IoT-based Technologies
}

\author{
Dr. Matteo Zallio, Dr. Damon Berry \\ Dublin Institute of Technology \\ ESHI - tPOT Research Group \\ Dublin, Ireland \\ matteo.zallio@dit.ie,damon.berry@dit.ie
}

\author{
Prof. Niccolò Casiddu \\ University of Genoa \\ DSA - Department of Sciences for Architecture \\ Genoa, Italy \\ casiddu@arch.unige.it
}

\begin{abstract}
The population of older adults will continuously increase over the coming decades. As they get older, people will require assistance and regular monitoring, with higher costs for welfare system and families. Two vital aspects of a healthy lifestyle, are domestic autonomy and maintenance of relationships within the neighborhood. This leads to an interesting research issue: "Could houses and appliances have the potential to improve autonomy and quality of life of citizens? Which methods and tools could enhance wellbeing and healthy conditions? The house has the potential to be a safe, adaptive environment, integrated with technologies for life support. This work seeks to investigate the key implications of architectural accessibility, interior Design features and interactive technologies, related to User Experience Design. The proposed Design approach called "Environment Design to Sustain Users" is based on a scenario composed of two empirical strategies. The reported research aims to support the creation of a new standard of houses in which people can live in a healthy way, enjoying the opportunities of ICT, which shall be "enabling" and integrated in an unobtrusive way so as to be accepted by the user.
\end{abstract}

Keywords - Design for All; ICT; Smart Home; Interaction Design; Human Factors; Ergonomics; User Centered Design; Ambient Assisted Living; Internet of Things; Smart Objects; Healthy Ageing; Accessible Homes; User Experience; Accessibility Systems \& Tools.

978-1-5090-4130-5

\section{INTRODUCTION}

Better global living conditions, a growing and ageing population, the development of new Design approaches and technologies are modifying the way we live within our houses, neighbourhoods and cities. Analysis, conducted by the European commission, on the population forecasts of those aged $70+$, indicate that this portion of the population will increase from 64 million in 2010 to 122 million in 2060 [1]. Contemporary infrastructures are required to increasingly provide continuous daily care of ageing people. The EC is already pursuing policy initiatives relevant to the active and healthy ageing of the population and to the Silver Economy, in particular on:

978-1-5090-4130-5/16/\$31.00 C2016 IEEE
- New markets such as renovation of building stock for independent living and senior tourism [1];

- Sustainable long-term care systems, on a life course and social investment approach to social protection systems and services [1];

- Increasing the potential of local communities and neighbourhoods in order to create a system where ageing people live within their usual context, with the indispensable aids provided by families, friends and caregivers by using innovative methods of communication such as ICT and IoT [2].

Projections show that from an economic point of view, in the future it will not be possible to use existing approaches to maintain a consistent level of healthcare for ageing population, many of whom are suffering from chronic diseases or minor psycho-physical deficits which require ever more medical attention [3]. One of the possible answers to this issue could be allowing ageing people, who are still in good health, to remain inside their houses for longer. Homes will need to become safer and adaptable environments, integrated with barrier-free features and smart technologies for people's assistance, without the presence of a personal caregiver. The multidisciplinary nature of the research, usees various tools for understanding different issues. Some of them are: the importance of Smart technologies (Cloud Computing and IoT) and the potential of ICT in people's life, cognitive and behavioural factors, habits and cultural aspects related to the ways of living at home for ageing people and the user-machine interaction [4] between new devices and senior users. The scientific relevance of the investigation topic, refers to the quantitative and qualitative case studies analysis, based on barrier-free, accessible and "LongLife friendly" houses of the last twenty-five years. The research method is based on the interrelation between the deductive method and the event study method [5]. In particular, the event study method is built on a statistical analysis of how events unfold during a defined period of time, in order to assess how the underlined features impact on each experience [6]. Improving the physical, relational and social capacities of ageing people is one of the core points that is examined in the research, through user feedback, collected within thirty-six literature based case studies. The case studies are analysed by extrapolating information from the existing literature, to 
pinpoint some of the important criteria needed to understand what are the most useful barrier-free features for senior people houses, how they interact with new technologies and what is their approach with new devices. The state of art for accessible homes, has been classified according to different categories and analysed by following the paradigms borrowed from different cross disciplines like the Design for All [7], the User Centred Design, the Universal Design and Inclusive Design and from the theories of User Experience Design and Human Computer Interaction disciplines, within the IoT-based technology point of view.

\section{STATE OF ART: INTERNET OF THINGS AND SMART OBJECTS FOR IMPROVING HEALTHY AGEING LIVING}

The potential of Smart Technologies and IoT to improve health, highly increased in the last few years [8], but IoT must be unified in its services or the potential gains will not emerge. The users have to trust that the services can be used all the time, that analytics of the population's health will be used for the common good, and for clearly visible short term individual benefit [2]. Care and personal aids at home are typically provided by local support services with the adoption of new devices and innovative, sustainable practices to postpone institutionalization. Some of these approaches could be employed in interactions between doctor and patient, via Internet (Skype or video-conference system), physical conditions monitored via wearable devices connected to the Cloud, house comfort, such as heating or cooling system controlled via remote. It is known that smart homes should become an instrument for supporting people and improve the performance of Activities of Daily Living. The house should be equipped not only with accessible, architectural features like elevators, corridors and doors large enough for wheelchairs, accessible furnishings, but also with the newest smart, wireless technologies that can turn traditional houses into an adaptive and responsive environment. If there is a need to integrate new disruptive technologies, it is important to underline that Design paradigms will change from the way that we currently design a house.

\section{A. Sensors and actuators for Senior Friendly homes}

Smart devices are considered to be part of the future of worldwide economic markets, especially in relation to the growing ageing population. On the basis of a recent survey from LinkAge society [9] conducted on 1789 users aged 65 and more, is possible to demonstrate that senior users represent a booming business in the technological consumer market. It showed that $41 \%$ of the users own a personal computer, while $61 \%$ own a cell phone and $31 \%$ an Internet connection. These data show that this generation of so-called "Silver Surfers" can offer an exponential growth of technologies and has a growing purchasing potential, unlike the market targeting the younger generation, that has a linear growth and a lower purchasing power [8]. Within this framework, it is possible to identify the potential of Assistive Technology and new innovations in the field of home automation in order to satisfy the needs of ageing people. The intention of this analysis is to merge different information from the capacities given by smart devices and the role of data analysis and machine learning, to the abilities and skills of older people to use objects, a few years ago they were not familiar with. By following this information, it is possible to outline the future trend of technological development by referring initially back to the early evolution of home automation.

Originally, around 1980's, houses with responsive technologies were known as a "Domotic Homes", and then became "Smart Homes", with a term coined in the late 1990's, together with wireless technology, Cloud Computing and the Internet of Things. One of the differences between a "Domotic House" and a "Smart - contemporary Home" is related to the type of connections that the sensors and actuators have. A Domotic House has cable connections, instead the Smart House use a good quantity of devices that communicate via wireless technology like Wi-Fi, 6LoWPAN Bluetooth SMART, Li-Fi, IR (InfraRed), NFC (Near Field Communication), BTLE (Bluetooth Low Energy) and ZigBee [10]. By using these different communication protocols, it is possible to allow the smallest devices with limited processing ability to transmit information wirelessly to a computer or in general to a "brain" that could transform the house into a SenseAble [11] adaptive environment. For example, thanks to different sensors and actuators that are currently present in the market, it is possible to:

- Easily control the temperature and humidity of the house with a smart thermostat;

- Control different light scenarios, by changing the traditional bulbs, with the new LED bulbs, with an integrated Wi-Fi module;

- Control sockets, with the new Wi-Fi plugs that could turn traditional appliances into programmable and adaptable devices;

- Control house security with smart IR sensors;

- Control personal safety by preventing fires, floods or blackouts;

- Monitor the lifestyle of citizens by using wearable devices like oximeters, blood pressure and heart rate monitor, posture and fall prevention systems [12];

- Communicate and socialize with social networks or robot companion.

All of these new technological systems features, also bring a different way to think and imagine our houses. In the near future there will be a drive to insert sensors and actuators in different areas of the house, integrated in the furniture, in walls, inside ceilings and floors. This is a disruptive paradigm of housing design, that could bring innovation and support for those people who can remain for longer in their houses. Today is possible to integrate different devices with a minimal economical and commissioning effort, thanks to the spreading and developing of low cost micro-controllers and technologies, but we need to underline that the majority of ageing people are not ready to use, interact and communicate with the smart objects. 


\section{USABLE AND ACCESSIBLE SMART ENVIRONMENTS: A FRAMEWORK OF THE SENIOR FRIENDLY HOUSE}

During the last Century, thanks to the progress of technology and the development of manufacturing techniques, there has been a large increase in the production of new tools that perform complex tasks independently [13].

This part of the research is intended as a review of a set of indications, useful to understand and identify the key points that the new ICT systems must have; what makes houses accessible and easy to use for an ageing person and how the user (with minor psycho-physical deficits) interacts with appliances, furniture, spaces and smart devices within the household scenario. The data collected with reference to a significant number of case studies of "Good Design Practice" and "Good Usage of Smart Technologies" are related to the user feedback.

The case studies, linked to theoretical knowledge will enable the creation of a User Feedback Evaluation diagram, that constitutes the catalogue of the indispensable and usable features that a Life-long house for ageing people should have. The set of studied features, that relate to the discipline of Interaction Design [14], will be used as a parameter to understand the level of usability and Affordance [15] of technological devices, with respect to the cognitive and behavioural factors, the human - built environment (HBE) and human - computer interaction (HCI).

\section{A. Case studies: housing and technologies}

The existing literature describes how social, educational, behavioural and welfare policies differ radically, depending on the country. A good example of this is the difference between the welfare model of Southern Europe in contrast with those applied in Anglo-Saxon, Scandinavian, Asian or American countries. The case studies were catalogued according to the construction chronology, divided into three geographical areas, starting from a global level, then narrowing it down to Europe and finally focusing on the Italian context. A valid tool for evaluating the complexity and usability of each experience is the analysis of different case studies, which were divided into four complementary categories: Co-housing, Assisted Homes, Private Homes, Expo - Research - Workshop Houses $[16,17,18,19]$. All the data examined in the three different contexts (Worldwide, European and Italian scenario) show different aspects of the "Passive" and "Active Technologies" that designers and caregivers included in different buildings.

The so called "Passive Technologies" refers to the group of architectural accessibility features, belonging to the User Centred Design and Design for All approaches, like:

- Design a safe continuous and step-free path or provide support with well-designed elevators;

- Minimum dimensions for doors and corridors that facilitate comfortable movement between spaces;

- Toilets that provides easy access, handles and a step-free shower access;

- Handrails for helping people in standing or resting.
- Use lighting system and surfaces that don't provide any aberrations or unpleasant reflections;

- Use colors to design a hierarchy between spaces, for people with Alzheimer or Dementia syndrome [20].

The "Active Technologies" are referred in general to the full set of smart communication systems such as:

- Systems for controlling the house comfort;

- Systems for monitoring people's health and safety;

- Systems for socialising and edutainment.

The case studies were finally estimated and classified by collecting feedback from primary and secondary users and feedback from experts and designers who worked or were related to each case study. Each case study has been analysed through the Evaluation chart (Fig. 1), which is a simply and quick method to visualize the level of features (referred to Passive, Active Technologies or User Feedback) with a scale from 1 to 10 .

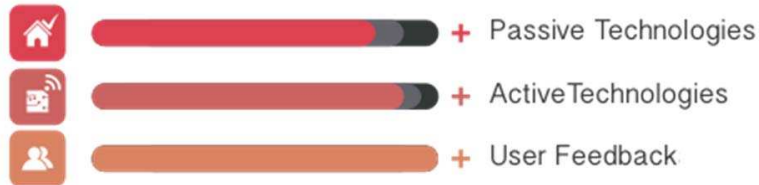

Fig. 1. Evaluation chart of Passive and Active Technologies and Users Feedback for each case study analysed.

Referring to the Passive Technologies, values from 0 to 5 indicate the lack of accessible features for a Senior Friendly house, values of 5 to 7 refer to basic and traditional aspects like minimum door and corridor width, low presence of stairs, accessible furnishings, while values from 8 to 10 refer to the highest level of architectural Design, dealing with accessibility and aesthetics, interior Design aspects. The Active Technologies refers to the quantity and quality of smart devices present in each case study. Values from 0 to 5 belong to the traditional electrical systems, while values from 5 to 7 refer to a more accurate level of technology usage, like sensors for light control, climate control, anti-flooding detector or smoke sensors and finally values from 8 to 10 , where technologies involved the most specific products available on the home automation market. Finally, the user feedback proposes a numeric scale of values from 0 to 5 for negative or unpleasant feedback and 6 to 10 for a positive feedback, generated among different users.

By integrating this information, from all the thirty-six case studies, it has been possible to define a summary diagram of user feedback. The "User Feedback Evaluation" diagrams (Fig. 2, 3, 4) represent, through the opinions of the primary users, secondary users and experts, designers and researchers directly involved in each case study, what are the positive and negative aspects related to each analysed experience.

From the point of view of the architectural features, focusing on the European and Italian context, the designer's awareness in recent years has been remarkable and the feedback results proven this theory $(100 \%$ positive feedback from primary and tertiary users on passive technologies within the European scenario) (Fig. 3). 


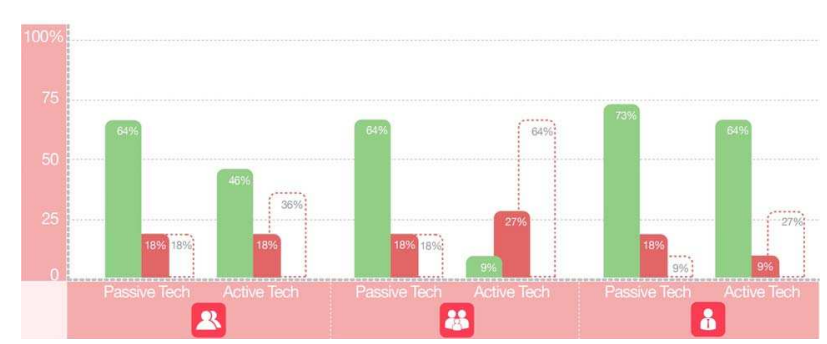

Fig. 2. User Feedback Evaluation of the Worldwide scenario.

The "democratization" of new technologies and more inclusive Design methods, show that over the past decade, according to European users and experts feedback, the perceived quality, usability and smartness of the houses is greatly improved.

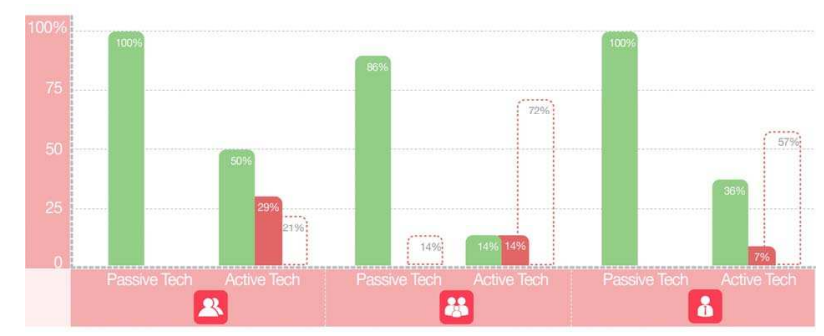

Fig. 3. User Feedback Evaluation of the European scenario.

In contrast, in the Italian context (Fig. 4), it is possible to underline that the process didn't grow as quickly as in Europe and the data shows that there is still a gap to be filled $(64 \%$ positive feedback from primary and secondary users and $90 \%$ from experts and designers). On the other hand, it is possible to confirm that, in the United States and Australia (Fig. 2), designers tend to refer to Universal Design method, while in Europe and Italy the methods usually used are the Design for All and Inclusive Design, which tend to be closer to the real needs of disadvantaged users and people with minor impairments. Data shows that the $64 \%$ of positive feedback from primary and secondary users is related to Passive Technologies, while only $48 \%$ of primary users express a positive feedback on the usage of Active Technologies. The point of view of experts, is slightly different, with $73 \%$ and $64 \%$ of positive feedback from their point of view.

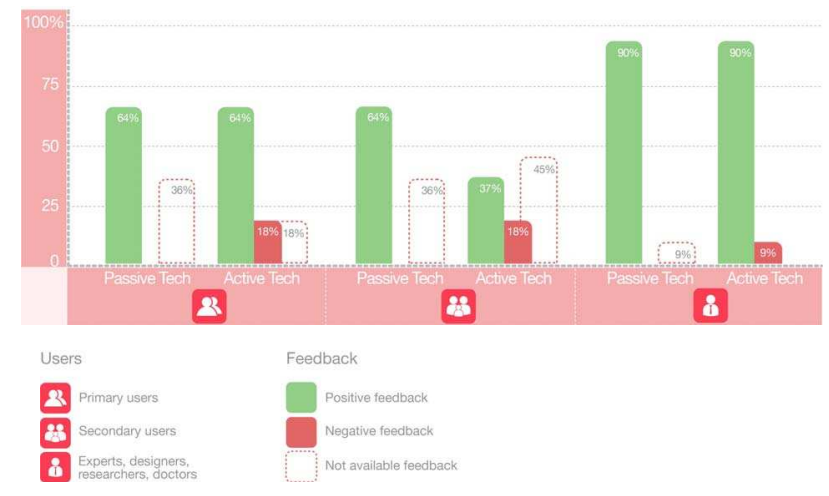

Fig. 4. User Feedback Evaluation of the Italian scenario.
According to this summary, it is possible to think that the range of results seen in the global context, compared to those found in the European area, are a direct result of the different approaches and Design methods used to design Senior Friendly houses [21]. It is possible to underline from the diagrams, which refer to the three examined scenarios, how the time factor and also the geographical location of each case study, played a key role in sensitizing designers, engineers and users in using architectural elements and technological devices for the development of Senior Friendly homes.

\section{ENVIRonment Design To Sustain Users: AdAPTIVE ENVIRONMENTS FOR ENABLING SENIOR CITIZENS}

The research, by using different existing guidelines, Design methods, case studies and user feedback, aims to define a new Design approach within the framework of a feasible future scenario, composed of two strategies. The "Environment Design to Sustain Users" approach, outlines new perspectives, new markets with an important impact on users and can be seen as a complement to other Design approaches (Design for All, User Centred Design, Universal Design, Inclusive Design, Interaction Design), with a defined focus on the relationship between ageing people needs, smart technologies and built environment.

The EDSU approach is based on to two strategies: one is the "Lifelong Housing Design", a strategy useful to design and build accessible and usable homes and one called "Lifelong Technological Integration" useful to identify and suggest which are the best features of different smart devices, integrated, in a simple and intuitive way within the home context, for supporting the life of householders. The two strategies are composed by merging the results and the user feedback of the theoretical research related to interior Design features and usable smart device for senior houses (Fig. 5).

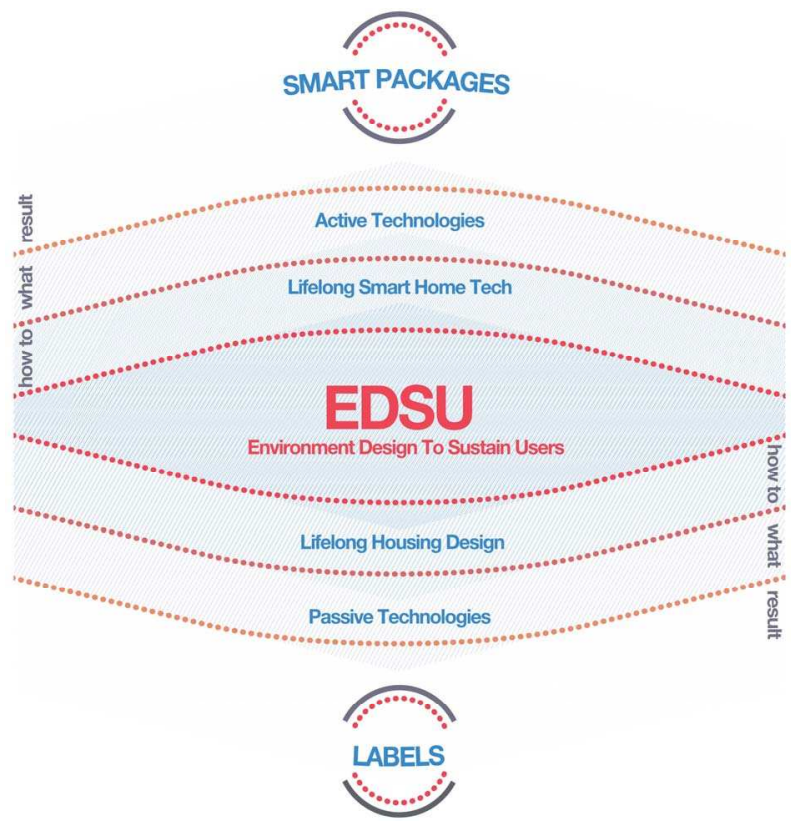

Fig. 5. Framework of the EDSU Approach and main impacts on the population. 


\section{A. Lifelong Housing Design}

One tangible result could be outlined with the instrument of the Labels which are part of the "Lifelong Housing Design" strategy. A new classification and evaluation method for the "Good Design Practices" that takes inspiration from the features summarized within the case studies analysis. It could be achieved, assessing factors such as accessibility, adaptability and flexibility of a barrier-free house.

It is possible to define three levels of certification for a "Lifelong Housing Design" ecosystem, that are composed of a group of guidelines and features (Green Label, Silver Label, Diamond Label) that professionals and users could benefit from, by creating and upgrading barrier-free, accessible houses for senior people. Each single Label is specifically customized, in order to enable people in reaching, by following different steps, the best compromise between costs and usability of a house. This standard model could improve the possibility of a certification, guaranteeing an added value to houses that can be certified as one of the following levels: "Green Label", "Silver Label", "Diamond Label". Each single label has different specific features, that constitute three different levels of depth and accuracy for designing barrier-free houses with smart appliances integrated in an unobtrusive way [22]. This strategy could have an impact on legislations and norms, because it could support people receiving funding or grants for improving or adapting homes and could increase the added value of barrierfree houses, that become automatically suitable for a wider number of users.

The solution takes inspiration from the Building Energy Consumption/rating (BER) and aims to impact on usability, accessibility and affordance aspects of houses and on interaction and cultural aspects for people. This labelling and certification system would trigger positive feedback and initiatives, for instance: it would help to easily identify the features of every certified home; ensure a higher quality Design of domestic spaces, with a reduction of the costs [23]; households could increase the market value by being able to attract a wider range of buyers, like ageing users, people with minor disabilities, families with young children, people who frequently use wheeled transportation aids; by refurbishing, adapting and upgrading to the next certification level, houses could become more competitive on the real estate market; governments could, at some point award tax benefits, whenever houses are improved following these principles.

The Labels could be developed within the real market as a graphic and a communicative tool, indicating the quality and quantity of architectural, accessible interior Design and "Longlife Friendly" elements, for a certified house. Moreover, this strategy takes into account the potentials of the new real estate market. In the near future, as shown by the data on the aging population, homes will be purchased by a growing number of people aged 50 and older, who have practical, functional and aesthetic needs as well as a greater technological knowledge than the older generations. The Labels will assume a great importance in promoting good accessible Design for those persons, bearing in mind that the majority of those who can afford to purchase or restore a house are over 45-50 years old.

\section{B. Lifelong Technological Integration}

The "Lifelong Technological Integration" strategy is developed in order to create a simple information and evaluation system that makes technology and devices more affordable and easy to use. The strategy is comprised of four Smart Packages divided into: Comfort Pack, Safety Pack, Family Pack and Healthy Pack. The aim of the Smart Packages is to become an information, communication and convenient classification tool, for supporting people in identifying and choosing different smart devices for various needs. The potential of this tool is to optimize the choice and the number of essentials devices, without over-equipping the house. In order to set up the classification method, it has been presented as a simple evaluation chart, which takes inspiration from the features analysed within the literature based case studies and existing UX Design approaches. The chart is composed by five elements: Affordance, Usability, Design, Plug and Play and Cost, referred to a traditional, not smart, comparable device. Each point of the chart has a number starting from 0 to 10 , which help the user in understanding the level of each single characteristic of the considered device (Fig. 6).
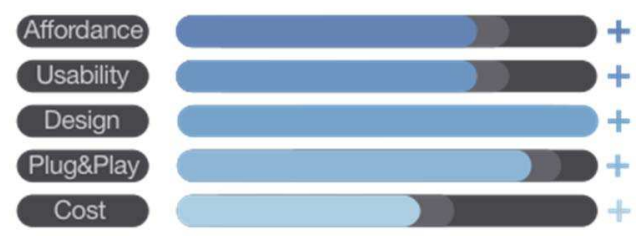

Fig. 6. Evaluation chart for the "User-Designed" smart device. The chart provides information to the users, for an easy understanding of features.

Each Smart Package contains a logo and an easy to understand set of functions, defined by colors and icons; all the $\operatorname{logos}$ and icons have been created from the analysis of communication codes and common languages which try to make the product more understandable, affordable and appealing. This evaluation and classification system could enable people to understand in a clear way how a device is suitable for their needs and this could be achieved thanks to two tools:

- The first one, simple and communicative: a label attached on the packaging of each smart product, which gives an immediate explanation of functions and features;

- The second is an information service or a web based application, designed to explain in detail if the object is easy to use, if it has a good Affordance [15, 24], if it is enjoyable and pleasant to see and use, if it is easy to install and if the cost, compared to a traditional, not smart object, is affordable or not.

The indications and the group in which the device is placed could increase the value of the products conforming to the features of the "Lifelong Technological Integration" strategy, in order to create devices that are marketable on a larger scale. Similar to the process defined for the "Lifelong Housing Design", the "Lifelong Technological Integration" strategy could become a new form of classification for the devices, simply by using the Smart Packages system. For example, if 
every technological device for the home has an additional simple and clear National or European labelling system applied on the packaging, the users would more benefit the potential of IoT and ICT for wellbeing and healthy living [25]. In the meantime, the distribution and the use of Smart systems would be considerably increased within the world consumer market and the attention to good Design, affordable and easy to interact smart devices, from the companies would certainly arise.

\section{CONCLUSION}

This research has sought to define a new Design approach, that is able to foresee future needs [26] of a growing ageing population and would improve the life's quality of senior people, who could remain in their own home for longer, in a safer way. The EDSU approach is created by merging different methods to analyse issues: from the user's point of view, to the guidelines belonging to different Design approaches and an holistic method. It can provide customised information related to additional Smart appliances, integrated in a "Long-life friendly" house. This could increase the quality of life within the built environment, improve the autonomy and sense of security and enhance the usage of smart devices for senior citizens. Two useful tangible implications of the strategies developed within the research could be: the creation of domestic systems, designed according to accessible and usable standards and smart devices, integrated in a non-invasive way, to simplify daily activities for the users, and improving the physical, relational and social capacities of ageing [27].

Despite the two methods, developed within the EDSU "Environment Design to Sustain Users" approach, are selfreferential and can be used separately, their synergy may create a comprehensive study on architectural, interior Design and technological features for designing a Senior Friendly home and suggest what improvements might be achieved. These strategies may also be useful indirectly to help the social and health system, by improving the European welfare system, pushing it from a model based around healthcare systems, to a system increasingly based on private home care. According to the data and the research carried out, this scenario underlines one of the possible and diversified solutions to raise awareness in Design culture, to increase the affordance of products and technology and to allow people the chance to live as long as possible in their own homes.

There are still many ways to improve critical issues related to the growing aging population [28]. But as a preliminary result of this research, an environment equipped with architectural facilities and integrated with smart objects, could improve people's quality of life, increase security, assist in daily activities, encourage socialising and become easy and manageable for caregivers, family and friends.

\section{REFERENCES}

[1] A.A. V.V., The 2012 Ageing Report: Economic and budgetary projections for the $27 \mathrm{EU}$ Member States (2010-2060), published by European Commission, 2012.
[2] AA.VV., Current Status of the World Health Survey, World Health Organization, New York, 2011.

[3] Victor C. R., Ageing, health and care, The policy press, Bristol, 2010.

[4] Moggridge B., Designing interaction, The MIT Press, Cambridge, 2007.

[5] Schaeken W., De Vooght G., Vandierendonck A., d'Ydewalle G., Deductive Reasoning and Strategies, Lawrence Erlbaum Associates, Mahwah - New Jersey, 1999.

[6] Binder J., The Event Study Methodology Since 1969, Kluwer Academic Publishers, 1998.

[7] Accolla A., Design for All. Il progetto per l'individuo reale, Franco Angeli, Milano, 2009.

[8] Furlonger D., Maverick Research: The future of technology belongs to the "Silver Surfer", in Gartner research, 25 September 2013.

[9] Orlov L. M., Technology Survey Age 65 to 100 - Extending Technology, Past the Boomers, A Study Sponsored by Linkage, 2011.

[10] Del Zanna G., Malavasi M., Vaccari G., Manuale illustrato per la domotica a uso sociale, Tecniche Nuove, Milano, 2009

[11] Ratti C., Biderman A., Outram C., SenseAble Cities, in "Das digitale Netz der Stadt", Stadt Bauwelt, pp. 69-75, Berlin, 2011.

[12] Patel S., Park H., Bonato P., Leighton C., Rodgers M., A review of wearable sensors and systems with application in rehabilitation, Journal of NeuroEngineering and Rehabilitation, 20 April 2012.

[13] Polillo R., Facile da usare, una moderna introduzione all'ingegneria della usabilità, Apogeo, Milano, 2010.

[14] Preece J., Rogers Y., Sharp H., Interaction Design, Apogeo, Milano, 2004.

[15] Gibson J.J., The Theory of Affordances. In R. Shaw \& J. Bransford, Perceiving, Acting and Knowing: Toward an Ecological Psychology, Wiley, Hoboken, 1977.

[16] A.A. V.V., Housing draft supplementary planning guidance, Greater London Authority City Hall, The Queen's Walk, London, 2011.

[17] A.A. V.V., AIA - The American Institute of Architects, Design for aging review 11: AIA design for aging knowledge community, Image Publishing Group, Victoria, 2012.

[18] Anderzhon J.W., Hughes D., Judd S., Kiyota E., Wijnties M., Design for Aging: International case studies of building and program, Wiley, Hoboken, 2012.

[19] CABE: Commission for Architecture and the Built Environment, Homes for our old age. Indipendent living by Design, in Women's Design Service and the University of the West of England, 2009.

[20] Fagnoni R., L'uso del colore per i malati di Alzheimer, un modo diverso di vedere il mondo, in Design e spazio terapeutico, a cura di Francesca Stabilini, Ed. Damiani, 2006.

[21] Cisneros H., Dyeramberlain M., Hickie J., Independent for life: homes and neighbourhoods for an aging America, University of Texas Press, Austin, 2012.

[22] Webb E. J., Campbell D. T., Schwartz R. D., Sechrest L., Unobtrusive Measures: nonreactive research in the social sciences. Rand McNally, Chicago, 1966.

[23] Zallio M., Design of a secure habitat for an enhanced long living: case study S.H.E.L.L. project. Paper: N. Casiddu, C. Porfirione, M. Zallio in Proceedigs of Ambient Assisted Living: Italian Forum 2014, pp. 397406, Springer, 2015.

[24] Norman D.A., Design of Everyday things, BasicBooks. 2013.

[25] Zallio M., Casiddu N., Life-long Housing Design: User Feedback Evaluation of Smart objects and Accessible houses for Healthy Ageing, in Proceedings of 9th PETRA Conference 2016, Corfù Island, Greece, ACM Digital Library, 2016.

[26] Norman D. A., Il Design del futuro, Apogeo, Milano, 2008.

[27] Zallio M., Home automation and technology: renewal of existing buildings, in Spadolini M. B., Design for better life. Longevità, scenari e strategie, pp. 102- 110, Franco Angeli, Milano, 2013.

[28] Tarricone R., Tsouros A. D., The Solid Facts, home care in Europe, in World Health Organization, Copenhagen, 2008. 